\title{
Influence of temperature fluctuations on equilibrium ice sheet volume
}

\author{
Troels Bøgeholm Mikkelsen, Aslak Grinsted, and Peter Ditlevsen \\ Centre for Ice and Climate, Niels Bohr Institute, Juliane Maries Vej 30, 2100 Copenhagen $\varnothing$, Denmark
}

Correspondence: Troels Mikkelsen (bogeholm@nbi.ku.dk)

Received: 27 March 2017 - Discussion started: 24 April 2017

Revised: 4 November 2017 - Accepted: 20 November 2017 - Published: 8 January 2018

\begin{abstract}
Forecasting the future sea level relies on accurate modeling of the response of the Greenland and Antarctic ice sheets to changing temperatures. The surface mass balance (SMB) of the Greenland Ice Sheet (GrIS) has a nonlinear response to warming. Cold and warm anomalies of equal size do not cancel out and it is therefore important to consider the effect of interannual fluctuations in temperature. We find that the steady-state volume of an ice sheet is biased toward larger size if interannual temperature fluctuations are not taken into account in numerical modeling of the ice sheet. We illustrate this in a simple ice sheet model and find that the equilibrium ice volume is approximately $1 \mathrm{mSLE}$ (meters sea level equivalent) smaller when the simple model is forced with fluctuating temperatures as opposed to a stable climate. It is therefore important to consider the effect of interannual temperature fluctuations when designing long experiments such as paleo-spin-ups. We show how the magnitude of the potential bias can be quantified statistically. For recent simulations of the Greenland Ice Sheet, we estimate the bias to be $30 \mathrm{Gtyr}^{-1}$ (24-59 $\mathrm{Gt} \mathrm{yr}^{-1}, 95 \%$ credibility) for a warming of $3{ }^{\circ} \mathrm{C}$ above preindustrial values, or $13 \%(10-25,95 \%$ credibility) of the present-day rate of ice loss. Models of the Greenland Ice Sheet show a collapse threshold beyond which the ice sheet becomes unsustainable. The proximity of the threshold will be underestimated if temperature fluctuations are not taken into account. We estimate the bias to be $0.12{ }^{\circ} \mathrm{C}$ $\left(0.10-0.18^{\circ} \mathrm{C}, 95 \%\right.$ credibility) for a recent estimate of the threshold. In light of our findings it is important to gauge the extent to which this increased variability will influence the mass balance of the ice sheets.
\end{abstract}

\section{Introduction}

Ice sheet mass balance has a nonlinear dependence on temperature. This behavior is observed in simple ice sheet models (Weertman, 1961, 1964, 1976; Roe and Lindzen, 2001) and in regional climate modeling of Greenland surface mass balance (SMB) (Fettweis et al., 2013), and the nonlinear effect of temperature on melt has been observed in Greenland river discharge (van As et al., 2017).

Ice sheets are characterized by a large interior plateau flanked by comparatively steeper margins. A warming will shift the equilibrium line altitude (ELA) to higher elevations, increasing the area exposed to melt. The area exposed to melt will increase nonlinearly with ELA because of the top-heavy hypsometry (van As et al., 2017). This mechanism explains the nonlinear dependence of mass balance on temperature for ice sheets where runoff is a significant fraction of the total mass balance. This mechanism is important for the mass balance of present-day Greenland but less so for present-day Antarctica where mass loss is dominated by solid ice discharge (Church et al., 2013, p. 1170). However, observations show that the response of Antarctic melt to temperature is nonlinear (Abram et al., 2013), while the potential for a large nonlinear response of Antarctic mass balance is particularly evident in the simulations from Pollard et al. (2015).

The nonlinear relationship between mass balance and warming means that there is an asymmetry in the response to cold vs. warm anomalies. Using a simple ice sheet model we will show how, as a consequence of this nonlinearity, the average mass balance will be different when forcing the model with a variable climate compared to a constant average climate. Simulations using constant climate will therefore be biased unless they make statistical corrections to allow for variance. Constant climate forcing is sometimes used to trace 
the long-term equilibrium response of ice sheet models as a function of temperature (e.g., Robinson et al., 2012).

Ice sheet modeling and evidence from paleoclimatic records indicate that ice sheets display a hysteresis response to climate forcing, indicating a critical threshold in temperature, a tipping point, beyond which an ice sheet becomes unsustainable (Abe-Ouchi et al., 2013; Robinson et al., 2012). This is a generic saddle-node bifurcation point, estimated by Robinson et al. (2012) to be reached for the Greenland Ice Sheet (GrIS) at a global warming of $+1.6^{\circ} \mathrm{C}\left(0.8-3.2^{\circ} \mathrm{C}\right)$ above the preindustrial value.

The stability of ice sheets is typically investigated by imposing a constant climate forcing and then letting the ice sheet model reach equilibrium (Huybrechts and de Wolde, 1999; Robinson et al., 2012; Solgaard and Langen, 2012). The hysteresis curve and collapse thresholds are then traced out by repeating these experiments for a range of temperatures and starting from ice-free conditions. However, this approach disregards the effects of interannual temperature variability.

That the surface mass balance of an ice sheet model is nonlinear with respect to temperature has previously been investigated in several studies. In a simplified model of continental ice sheets, Roe and Lindzen (2001) show that the total annual ablation scales with the cube of temperature at the ice sheet margin. Ridley et al. (2010) specifically avoid using average monthly temperature and precipitation climatologies and instead use time series from individual months in order to include the effect of interannual variability in their study. Fettweis et al. (2013, see Fig. 6h) investigate the GrIS SMB simulated by regional climate models (RCMs) as a function of mean surface temperature from general circulation models (GCMs). Our contribution is a quantification of this effect and an estimate of the necessary bias correction to surface temperature needed to account for temperature fluctuations in long-term ice sheet simulations.

Previous studies of natural variability in the context of ice sheets include Fyke et al. (2014), who found that the variability in the GrIS surface mass balance will increase in a warmer climate due to increased ablation area, and Roe and O'Neal (2009), who found that large fluctuations in glacier extent can be driven by natural, fast fluctuations in climate. Sub-annual temperature variability in the context of positive-degree-day (PDD) models is investigated in, for example, Arnold and MacKay (1964), Reeh (1991), Hock (2003), Calov and Greve (2005), Seguinot (2013), and Wake and Marshall (2015). PDD models connect surface melting and air temperature and are used extensively due to their simplicity and wide availability of air temperature data (Hock, 2003). Seguinot (2013) compares the Greenland SMB calculated from four different annual PDD formulations with a reference SMB calculated from a PDD scheme using a monthly air temperature and precipitation climatology and deviations from a long-term interannual mean. On the scale of sub-annual climatology, there are large uncertainties as the estimates of the SMB dif- fer significantly depending on the simplifying assumptions used in the PDD formulation, highlighting the need to accurately model both spatial and temporal variability. These findings are built upon by Wake and Marshall (2015), who found that the standard deviation of monthly average temperature may be represented as a quadratic function of monthly average temperature. In the present study we are concerned with interannual variability and expect our results to apply independently of the chosen SMB model.

We investigate how climate variability influences the mass balance of ice sheets with a nonlinear response to climate forcing. We derive a simple statistical relationship which can be used to quantify the effect and illustrate why it matters on a minimal ice sheet model. We then proceed to show how this may be applied to published results from a coupled ice sheet model. In Sect. 2 we derive an analytical relationship between the magnitude of temperature fluctuations and ice sheet volume, assuming a simple relationship between the mass balance, temperature and ice sheet volume. This relationship is shown to hold using a simple ice sheet model (that includes a surface mass balance model) in Sect. 3, and in Sect. 4 we estimate the consequences of temperature fluctuations on a recent long-term ice sheet study (Robinson et al., 2012), assuming the effect of temperature fluctuation presented here is not already accounted for. The limitations of this approach, as well as further possible applications, are discussed in Sect. 5.

\section{The mass balance of an ice sheet}

\subsection{A minimal ice sheet model}

In order to investigate the influence of temperature fluctuations on the mass balance we consider a simple ice sheet model introduced by Oerlemans (2003) hereafter denoted Oer03. This model describes the essential dynamics of an ice sheet assumed to be axially symmetric and resting on a bed that slopes linearly downwards from the center. The ice is modeled as a perfectly plastic material, and the ice sheet is coupled to the surrounding climate by adjusting the height of the equilibrium line $h_{\mathrm{Eq}}$ (Oerlemans, 2008):

$h_{\mathrm{Eq}}=h_{E, 0}+(T-\bar{T}) \cdot 1000 / 6.5$.

Equation (1) represents an increase in the equilibrium line altitude of roughly $154 \mathrm{~m}^{\circ} \mathrm{C}^{-1}$. The influence of $h_{\mathrm{Eq}}$ on the specific balance $B$ is illustrated in Fig. 1. It should be noted that the simple relationship described by Eq. (1) does not capture situations where the SMB may increase with increasing temperature, as discussed in Sect. 5. Further details of the Oer03 model allowing the formulation in Eq. (2) below are described in the Supplement.

The model is chosen for its simplicity; thus, it is not accurately modeling a specific ice sheet. The two main rea- 


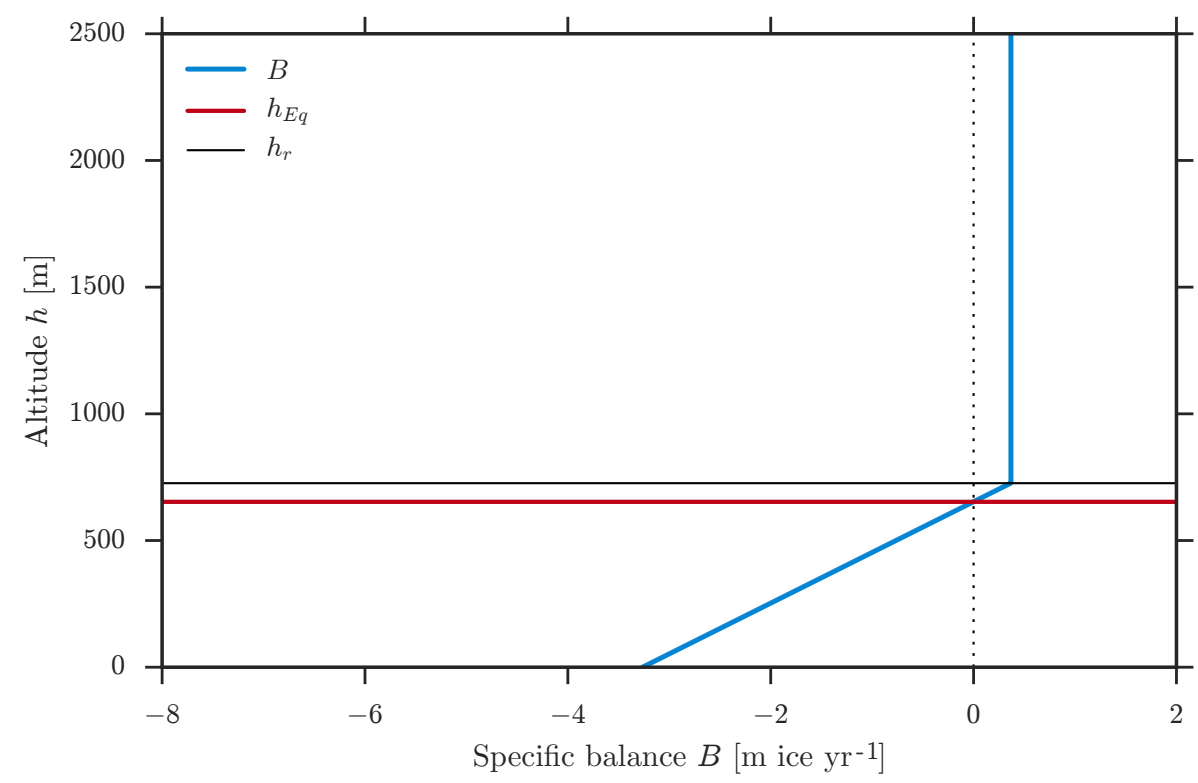

Figure 1. Specific balance $B$ for $\bar{T}=0$ from Eq. (1) using the parameters in Table 1 and Eqs. (S3)-(S4) of the Supplement. $h_{\mathrm{Eq}}$ denotes the equilibrium line. The runoff line $h_{\mathrm{r}}$ specifies the simplified climatic conditions, as the specific balance is constant above $h_{\mathrm{r}}$ (see also Supplement, Eq. S4) and the balance gradient is constant below $h_{\mathrm{r}}$ (Oerlemans, 2003).

sons for choosing it for our analysis are: (1) the simplicity of Oer03 allows the analytical approach detailed below and (2) the Oer03 model shows the same functional relationship between surface mass balance and temperature as has been found for regional climate models for a range of temperature scenarios (Fettweis et al., 2013). The change in volume or mass of the ice sheet depends on the balance between accumulation, ablation and ice sheet discharge which in turn depends on both the interplay between the fluctuating temperature and the state of the ice sheet itself.

Before proceeding with the simple model, we investigate the effect of interannual temperature fluctuations by considering the ice sheet as a simple dynamical system. We assume that the temporal change in volume of the ice sheet depends only on the volume $V$ itself and a single time-varying mean temperature over the ice sheet, $T$. The mass balance (change in ice sheet volume) is denoted as $\mathrm{d} V / \mathrm{d} t$,

$\mathrm{d} V / \mathrm{d} t=f(T, V)$,

where $f(T, V)$ is some nonlinear function. The (stable) fixed point, $f(T, V)=0$, corresponds to a balance between loss and gain in the ice volume. This is in general an implicit equation to determine the steady-state volume $V_{0}(T)$ as a function of temperature, such that $f\left(T, V_{0}(T)\right)=0$.

However, the fixed point is not identical to the statistically steady-state volume with a temporally fluctuating temperature $T_{t}=T(t)$ with expectation value $\left\langle T_{t}\right\rangle=\bar{T}$. A numerical integration to equilibrium of an ice sheet model with and without interannual fluctuating temperature shows that in steady state the ice sheet volume $V_{t}$ will fluctuate around $\left\langle V_{t}\right\rangle=\bar{V}$, where $\bar{V}$ is systematically smaller than the corresponding $V_{0}(T)$ (Fig. 2). In Fig. 2, $\bar{T}$ is shown on the horizontal axis in the right panel, and the corresponding $\bar{V}$ is shown on the vertical axis (both panels).

Since the temperature $T_{t}$ - and thus the ice sheet volume $V_{t}-$ is a stochastic variable, the following will characterize an equilibrium state:

$\left\langle f\left(T_{t}, V_{t}\right)\right\rangle=0$.

To calculate $\bar{V}$ we perform a Taylor expansion of Eq. (3) around the - presently unknown - steady state $(\bar{T}, \bar{V})$ and calculate the mean volume $\bar{V}$. We use the notation $f_{T}:=$ $\frac{\partial f}{\partial T}, f_{\mathrm{TV}}:=\frac{\partial^{2} f}{\partial T \partial V}$, etc. Furthermore, $f^{0}:=f(\bar{T}, \bar{V}), f_{T}^{0}:=$ $\left.\frac{\partial f}{\partial T}(T, V)\right|_{(\bar{T}, \bar{V})}$, etc. We then get

$$
\begin{aligned}
\left\langle f\left(T_{t}, V_{t}\right)\right\rangle= & f^{0}+\left\langle T_{t}-\bar{T}\right\rangle f_{T}^{0}+\left\langle V_{t}-\bar{V}\right\rangle f_{V}^{0} \\
& +\frac{1}{2}\left\langle\left(T_{t}-\bar{T}\right)^{2}\right\rangle f_{\mathrm{TT}}^{0}+\frac{1}{2}\left\langle\left(V_{t}-\bar{V}\right)^{2}\right\rangle f_{\mathrm{VV}}^{0} \\
& +\left\langle\left(T_{t}-\bar{T}\right)\left(V_{t}-\bar{V}\right)\right\rangle f_{\mathrm{TV}}^{0}+\mathcal{O}(3),
\end{aligned}
$$

where $\mathcal{O}(3)$ represents higher order terms. We can simplify Eq. (4) considerably: first note that since $\bar{T}$ is the expectation value of $T_{t}$ we have $\left\langle T_{t}-\bar{T}\right\rangle=\left\langle T_{t}\right\rangle-\bar{T}=\bar{T}-\bar{T}=0$ and with the same argument $\left\langle V_{t}-\bar{V}\right\rangle=0$. The quantity $\left\langle\left(T_{t}-\bar{T}\right)^{2}\right\rangle$ is the variance of the fluctuating temperature - we will assume this is known in simulations and substitute $\left\langle\left(T_{t}-\bar{T}\right)^{2}\right\rangle=\sigma_{T}^{2}$. Since the temperature variations are small with respect to the mean and have a symmetric distribution, we may neglect higher order terms in Eq. (4) (Rodriguez and Tuckwell, 


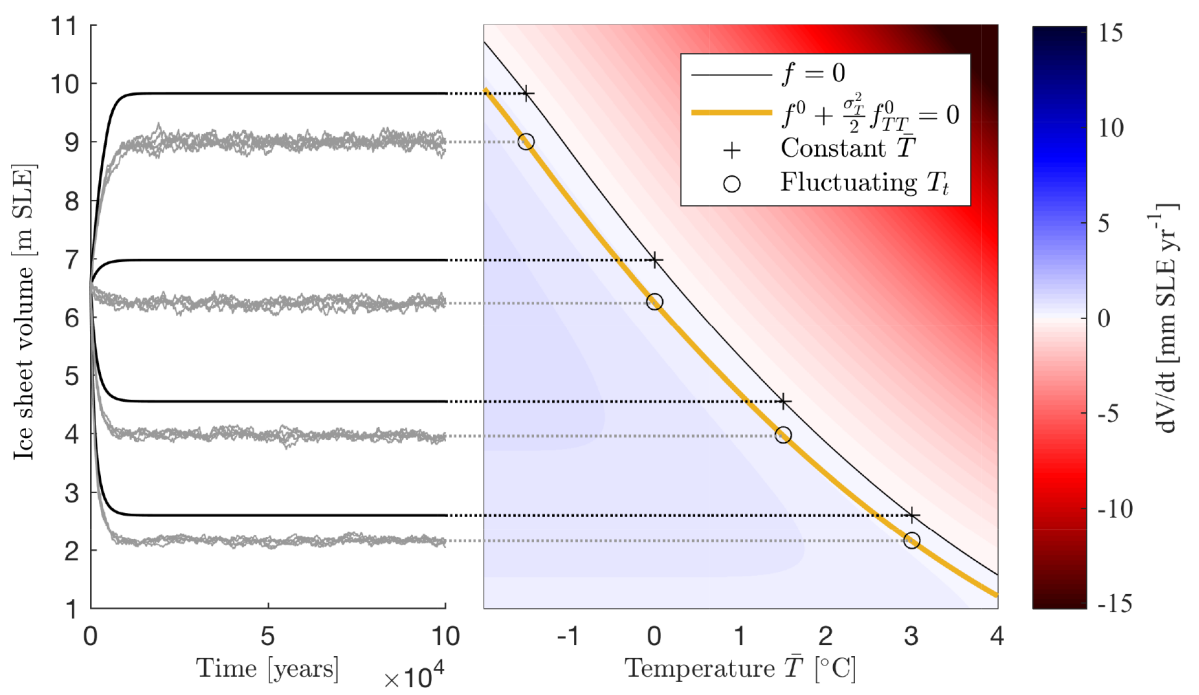

Figure 2. (Left) Simulations of the Oer03 model for $\bar{T}=-1.5,0,1.5$ and 3 . The black curves denote a constant temperature and the grey curves denote fluctuating temperatures generated with Eq. (8). (Right) The mass balance Eq. (2) for the Oer03 model in the ( $T$, $V$ ) plane. The black contour is the steady-state $f=\mathrm{d} V / \mathrm{d} t=0$. The markers represent the average of the numerical simulation with constant ( + ) and fluctuating (o) temperature seen on the left. Finally the yellow contour shows the approximation derived in Eq. (6).

1996). We are left with

$$
\begin{aligned}
\left\langle f\left(T_{t}, V_{t}\right)\right\rangle \approx & f^{0}+\frac{\sigma_{T}^{2}}{2} f_{\mathrm{TT}}^{0}+\frac{1}{2}\left\langle\left(V_{t}-\bar{V}\right)^{2}\right\rangle f_{\mathrm{VV}}^{0} \\
& +\left\langle\left(T_{t}-\bar{T}\right)\left(V_{t}-\bar{V}\right)\right\rangle f_{\mathrm{TV}}^{0} .
\end{aligned}
$$

We have evaluated the last two terms in Eq. (5) numerically for the Oer03 model and found that $\left\langle\left(V_{t}-\bar{V}\right)^{2}\right\rangle$ and $\left\langle\left(T_{t}-\bar{T}\right)\left(V_{t}-\bar{V}\right)\right\rangle$ tend to zero as the ice sheet approaches equilibrium volume (Fig. S3, Supplement) - neglecting the last two terms, Eq. (5) reduces to

$\left\langle f\left(T_{t}, V_{t}\right)\right\rangle \approx f^{0}+\frac{\sigma_{T}^{2}}{2} f_{\mathrm{TT}}^{0}$.

Equation (6) is the main observation in this work. We shall in the following estimate the implications of this result on realistic asynchronously coupled state-of-the-art ice sheet climate model simulations. As $\left\langle f\left(T_{t}, V_{t}\right)\right\rangle=0$ at the steady state it can be seen from Eq. (6) that

$$
\begin{gathered}
0=f^{0}+\frac{\sigma_{T}^{2}}{2} f_{\mathrm{TT}}^{0} \Rightarrow \\
f^{0}=-\frac{\sigma_{T}^{2}}{2} f_{\mathrm{TT}}^{0}>0
\end{gathered}
$$

since $f_{\mathrm{TT}}^{0}<0$ - this negative curvature of $f^{0}$ is the nonlinear effect causing the bias. $V_{0}(T)$ is the stable fixed point; $f\left(T, V_{0}(T)\right)=0$ - thus $f(T, V)>0$ for $V<V_{0}$ and $f(T, V)<0$ for $V>V_{0}$. This together with Eq. (7) implies that $\bar{V}<V_{0}$; that is, a positive temperature anomaly increases the mass loss more than what can be compensated for by an equally large negative anomaly (van de Wal and Oerlemans, 1994).

\section{Ice sheet simulations}

\subsection{Fluctuating temperatures}

To generate an ensemble of volume simulations we use time series $T_{t}$ comparable to the observed temperatures over Greenland between year 1851 and 2011. For this we use the AR(1) process (Hasselmann, 1976; Frankignoul and Hasselmann, 1977; von Storch and Zwiers, 2003; Mudelsee, 2010):

$T_{t+1}=\bar{T}+a \times\left(T_{t}-\bar{T}\right)+\sigma_{\mathrm{AR}} W_{t}$,

where $W_{t}, t=1,2, \ldots$ are independent, random draws from a standard normal distribution. The exact form of the model used for generating temperature time series $T_{t}$ is of less importance than the variance of the resulting $T_{t}$ as only the variance enters into Eq. (6).

The parameters $\left(a, \sigma_{\mathrm{AR}}^{2}\right)$ were obtained by fitting Eq. (8) to the observed annual mean temperatures over Greenland between years 1851 and 2011 (Supplement). We obtain $\left(a, \sigma_{\mathrm{AR}}^{2}\right)=(0.67,0.85)$; thus, the $\mathrm{AR}(1)$ process Eq. (8) has variance (Box et al., 2008) $\sigma_{T}^{2}=\sigma_{\mathrm{AR}}^{2} /\left(1-a^{2}\right)=1.54{ }^{\circ} \mathrm{C}^{2}$.

As we quantify the effect of interannual stochastic variability we use annually averaged temperatures, consistent with the formulation of the Oer03 model (see Table S1 of the Supplement). We find time step size of 1 year to be sufficient for integrating the Oer03 model (Fig. S1); thus, $T_{t+1}$ in Eq. (8) represents the temperature 1 year after $T_{t}$.

To find the steady-state volume we run the Oer03 model forward long enough for the ice sheet to reach equilibrium, with and without fluctuating temperatures. The results of this procedure are shown in Fig. 2 (left) where it is clearly seen that the steady-state volume is smaller for simulations with 
fluctuating temperatures than with constant temperature. We emphasize that the fluctuating temperature time series $\left\{T_{t}\right\}$ have as mean the constant temperature, $\left\langle T_{t}\right\rangle=\bar{T}$, so that the differences are due only to the annual temperature fluctuation.

In Fig. 2 (right) the effect of temperature fluctuations is shown in the $(T, V)$ plane: the markers "+" are steady states of numerical simulations with constant temperature, while the circles represent ensemble averages of simulations with fluctuating temperatures. It is evident that temperature fluctuations decrease the steady-state ice volume. The yellow curve in Fig. 2 (right) was calculated using Eq. (6) and gives a good agreement with the results from ensemble simulations.

In order to illustrate the physics behind Eq. (6), consider values of the mass budget function $f$ for different ice sheet volumes $V$ (shown in Fig. 3). The insert shows, for a particular value of $V$, how the steady state is influenced by fluctuating temperatures: the average mass budget of a colder year and a warmer year is less than the mass budget of a year with a temperature corresponding to the average of "cold" and "warm"; to put it another way, the increased SMB of a single anomalously cold year cannot balance the increased melt from an equally anomalously warm year (van de Wal and Oerlemans, 1994). In particular let $T_{c}=\bar{T}-\sigma$ and $T_{h}=\bar{T}+\sigma$ :

$$
\frac{f\left(T_{c}, V\right)+f\left(T_{h}, V\right)}{2}<f\left(\frac{T_{c}+T_{h}}{2}, V\right) \text {, }
$$

which is consistent with $f_{\mathrm{TT}}^{0}<0$ as shown in Eq. (7).

\section{Consequences for long-term ice sheet simulations}

Here we investigate the effect of accounting for fluctuating temperatures when running long timescale climate simulations. These can be either transient runs, scenarios with specified changing $\mathrm{CO}_{2}$ forcing or equilibrium runs with specified constant forcing. Specifically, we analyze the results of Robinson et al. (2012) where the long-term stability of the GrIS is investigated. In that study, an ice sheet model is forced by the output of a regional climate model driven by the ERA40 climatology with a constant temperature anomaly applied (see Robinson et al., 2012, and the Supplement).

As parameters in ice sheet models are often tuned to reproduce an observed ice sheet history from a time series of forcing observations (e.g., Muresan et al., 2016), the ice sheet volume bias we describe may already be implicitly compensated for. To estimate the size of the temperature fluctuation bias, we assume that this bias has not already been accounted for by parameter tuning.

Fettweis et al. (2013) compare the output of RCMs forced with multiple future climate scenarios and show that the effect of rising temperature on the GrIS SMB is well described by a third-degree polynomial, which is consistent with the aforementioned findings of Roe and Lindzen (2001). The reader may note the qualitative similarities between Fig. 3 in the present article and Fig. 6h in Fettweis et al. (2013). We follow Fettweis et al. (2013), and to the ensemble of simulations in Robinson et al. (2012) we fit third-degree polynomials to the SMB as a function of temperature at time $t=200$ years (see also the Supplement) and obtain thirddegree polynomials in $T$ :

$\left\{\widetilde{f}_{i j}(T) \mid \widetilde{f}_{i j}(T)=A_{i j} T^{3}+B_{i j} T^{2}+C_{i j} T+D_{i j}\right\}$,

where the indices $i$ and $j$ run over two separate parameters in the model that take 9 and 11 values, respectively (Robinson et al., 2012), so in total we have 99 unique polynomial fits. These polynomials are then used as a simple description of the mass balance function as a function of temperature, $\operatorname{SMB}_{i j}(T)=\widetilde{f}_{i j}(T)$. Differentiating twice we obtain $\widetilde{f}_{\mathrm{TT}}(T)=6 A T+2 B$ (suppressing indices $i$ and $j$ for clarity).

For all parameter pairs $(i, j)$ we evaluate $\widetilde{f}(T)$ and $\widetilde{f}(T)+$ $\left(\sigma_{T}^{2} / 2\right) \widetilde{f}_{\mathrm{TT}}(T)-$ this is shown in Fig. $3 \mathrm{~b}$ as the full and dotted lines, respectively.

To illustrate this approach we pick a specific temperature $T_{0} . \widetilde{f}\left(T_{0}\right)$ is thus the SMB for a constant temperature and $\widetilde{f}\left(T_{0}\right)+\left(\sigma_{T}^{2} / 2\right) \widetilde{f}_{\mathrm{TT}}\left(T_{0}\right)$ represents the effect of letting the temperatures fluctuate. This procedure gives us an expression for $\triangle \mathrm{SMB}$ :

$$
\begin{aligned}
\Delta \mathrm{SMB} & =\widetilde{f}\left(T_{0}\right)-\left[\widetilde{f}\left(T_{0}\right)+\frac{\sigma_{T}^{2}}{2} \widetilde{f}_{\mathrm{TT}}\left(T_{0}\right)\right] \\
& =-\frac{\sigma_{T}^{2}}{2} \widetilde{f}_{\mathrm{TT}}\left(T_{0}\right),
\end{aligned}
$$

where $\triangle \mathrm{SMB}$ is positive in accordance with Eq. (7). Next we find the temperature difference $\Delta T$ such that

$\tilde{f}\left(T_{0}-\Delta T\right)+\frac{\sigma_{T}^{2}}{2} \widetilde{f}_{\mathrm{TT}}\left(T_{0}-\Delta T\right)=\widetilde{f}\left(T_{0}\right)$.

In this way $\Delta T$ is the effective temperature change resulting from considering fluctuating temperatures.

The results of applying the steps outlined above on the data from Robinson et al. (2012) are shown in Fig. 4. The red curves in Fig. 4 show the most likely $\Delta T$ and $\triangle \mathrm{SMB}$; the grey curves are estimates for the $9 \times 11$ individual parameter values and the blue shaded area represents the $95 \%$ credibility region.

The warmings quoted in Robinson et al. (2012) are relative to the preindustrial period, whereas the reported warming from the preindustrial period to the present day is estimated to $1^{\circ} \mathrm{C}$ (Stocker et al., 2013, p. 78). Following the RCP45 scenario it is more likely than not that Earth will experience a further warming of $2.0^{\circ} \mathrm{C}$ (IPCC, 2013, p. 21) from today to the year 2100 . Combining these numbers we arrive at a warming of $3.0^{\circ} \mathrm{C}$ in the year 2100 relative to the preindustrial period when considering the RCP45 scenario. For this value it can be seen on Fig. 4 (top) that an 

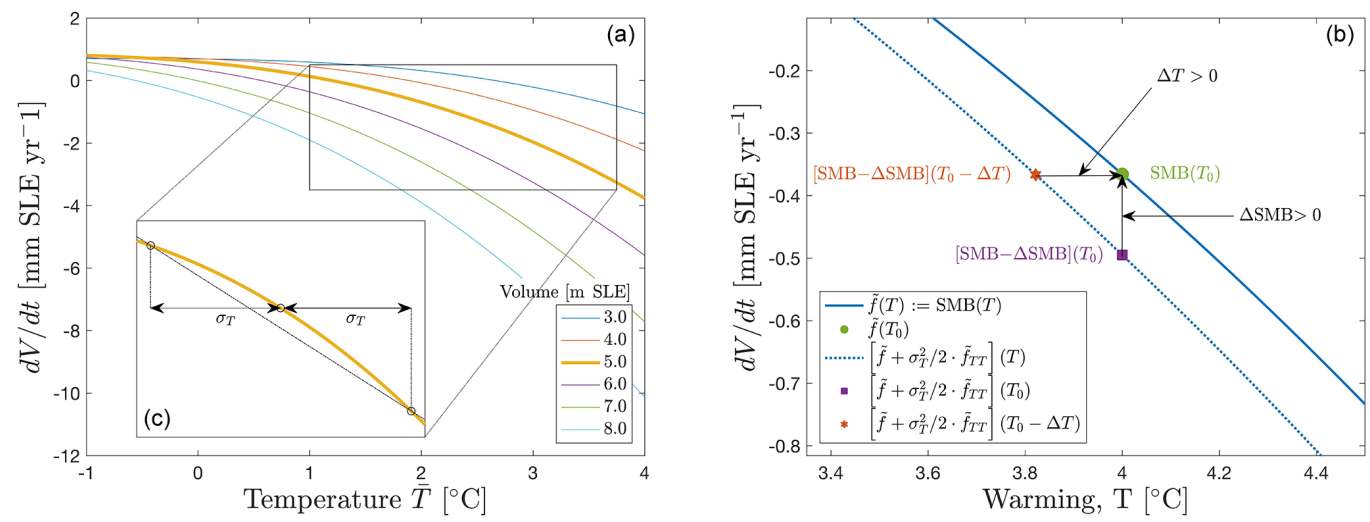

Figure 3. (a) Mass balance $\mathrm{d} V / \mathrm{d} t$ of the ice sheet for different values of the total ice sheet ice volume $V$ in the Oer03 model. Similar to Fig. 2 but here we show $\mathrm{d} V / \mathrm{d} t$ as a function of $\bar{T}$ for different total volumes $V$. (c) The curvature of $\mathrm{d} V(\bar{T}) / \mathrm{d} t$ influences the steady-state behavior - a cold year does not cancel out the effect of an equally warm year as shown in Eq. (9). The value of $\sigma_{T}$ is used for illustration and is given as the square root of the temperature variance, $\sigma_{T}=\sqrt{1.54{ }^{\circ} \mathrm{C}^{2}}=1.24^{\circ} \mathrm{C}$. Note the similarity of the $\mathrm{d} V(\bar{T}) / \mathrm{d} t$ found here to Fig. $6 \mathrm{~h}$ in Fettweis et al. (2013). (b) Estimating the effect of fluctuating temperatures on GrIS projections. The full curve is obtained by fitting a thirddegree polynomial $\tilde{f}(T)$ to an $\operatorname{SMB}(T)$ from Robinson et al. (2012). The dotted line shows the effect of temperature fluctuations obtained by applying Eq. (6). For a warming of $4^{\circ} \mathrm{C}$ the green circle shows the SMB. $\triangle$ SMB is obtained by applying Eq. (11) and represents the change in mass balance resulting from the temperature fluctuations. $-\Delta T$ is the temperature change required to negate this effect and is obtained implicitly from Eq. (12).
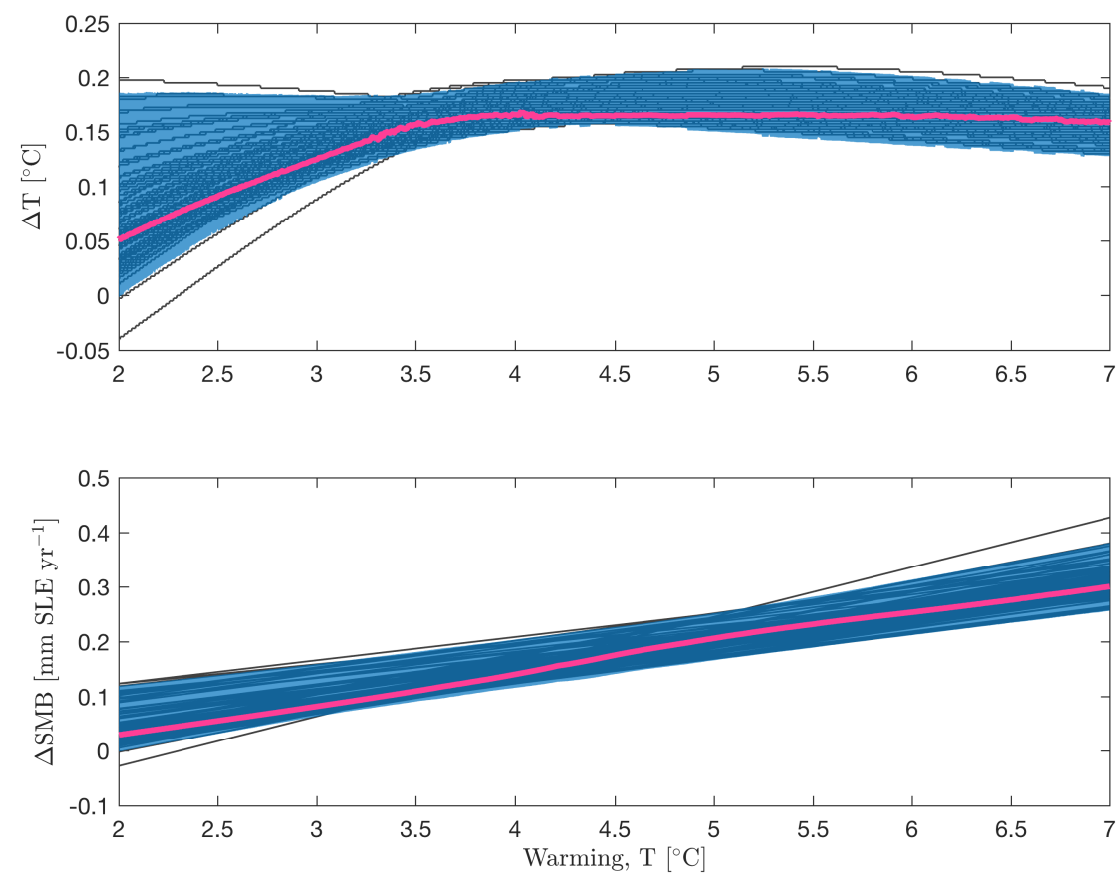

Figure 4. Maximum likelihood estimates of $\Delta T$ (effective temperature change) and $\Delta \mathrm{SMB}$ (effective SMB change where positive values correspond to SMB loss, red curves) resulting from a given temperature increase. $\Delta T$ and $\Delta \mathrm{SMB}$ defined as in Fig. $3 \mathrm{~b}$. The grey curves are estimates from individual simulations and the blue shaded area denotes $95 \%$ credibility regions.

additional $0.12{ }^{\circ} \mathrm{C}\left(0.10-0.18{ }^{\circ} \mathrm{C}, 95 \%\right.$ credibility) should be added to any constant warming term when considering simulations of the Greenland Ice Sheet, assuming the same temperature variance as in Sect. 3. We note that this bias correction is small compared to the spread in temperature pro- jections. Nevertheless this is a known bias that should be accounted for. The threshold for GrIS ice loss has been estimated to be at $+1.6{ }^{\circ} \mathrm{C}\left(0.8-3.2{ }^{\circ} \mathrm{C}\right)$ (Robinson et al., 2012). Applying the bias correction above indicates that the threshold for GrIS may be $0.12^{\circ} \mathrm{C}\left(0.1-0.18^{\circ} \mathrm{C}\right)$ colder (Fig. 4, 
top). This is not a large adjustment considering other uncertainties, but it places additional constraints on the maximum temperature increase admissible to avoid passing this threshold and the corresponding multi-millennial sea level commitment. Figure 4 (bottom) shows the most likely $\triangle \mathrm{SMB}$ resulting from temperature fluctuations at a $3{ }^{\circ} \mathrm{C}$ warming to be $30 \mathrm{Gtyr}^{-1}$ (24-59 $\mathrm{Gt} \mathrm{yr}^{-1}, 95 \%$ credibility) or - for context $-30 \mathrm{Gt} \mathrm{yr}^{-1}\left(24-59 \mathrm{Gt} \mathrm{yr}^{-1}, 95 \%\right.$ credibility) of the average GrIS SMB of $-234 \pm 20 \mathrm{Gt} \mathrm{yr}^{-1}$ reported for the period 2003-2011 (Barletta et al., 2013).

Observe in Fig. 4 that $\Delta T$ goes to zero for low temperature anomalies and appears to reach a constant value for higher temperature anomalies. In the framework presented here this can be explained by considering the $\operatorname{SMB}(T)$ curves shown in Fig. 3a. For low temperature anomalies the $\operatorname{SMB}(T)$ curve in Fig. $3 \mathrm{a}$ is close to flat so the second derivative is small; this gives a small contribution to $\triangle \mathrm{SMB}$ from Eq. (11). On the other hand, as the $\operatorname{SMB}(T)$ curve in Fig. 3a becomes progressively steeper, a correspondingly smaller $\Delta T$ in Eq. (12) is required to compensate for $\triangle \mathrm{SMB}$.

The results above highlight that interannual temperature variability cannot be neglected in long-term studies involving ice sheet models. The straightforward approach would be to simply include the expected temperature variability in a number of simulations followed by calculating the ensemble average. Conversely, one could calculate the effect of temperature variability for a range of climate scenarios as a starting point for a following bias adjustment.

\section{Conclusions}

From a theoretical argument and by considering a minimal model of an ice sheet we have shown that fluctuating temperatures forcing the ice sheet have an effect on the mass balance and thus on the steady-state volume of the ice sheet (Eq. 6 and Fig. 2). The effect is explained by the curvature, or second derivative, of the mass balance as a function of temperature.

Temperature fluctuations can be accounted for in ice sheet modeling studies, either explicitly (e.g., Ridley et al., 2010; Seguinot, 2013) or implicitly, as happens when tuning the ice sheet model to reproduce an observed ice sheet history with observed forcing as input (e.g., Muresan et al., 2016). Temperature fluctuations may also be explicitly accounted for by forcing the ice sheet model with climate model output that reproduces the magnitude of the observed interannual temperature variability. Our results show the importance of considering temperature fluctuations in the mass balance schemes before bias correcting for other possible model deficiencies.

We find that the steady-state ice sheet volume in Oer03 is 0.5-1 m SLE (meters sea level equivalent) smaller when the minimal model is forced with fluctuating temperatures compared to constant temperature (Fig. 2). It is therefore necessary to consider the impact of temperature variability when designing long-term model experiments such as paleo-spinups (Bindschadler et al., 2013; Golledge et al., 2015; Nowicki et al., 2016), especially when downsampling the paleoforcing series. Though differences between ice sheet models may be larger than the effect of temperature fluctuations estimated here, we expect the effect to be in the same direction and of similar magnitude for all models. Furthermore, models of sub-shelf melting, grounding line migration and ice discharge have the potential to respond nonlinearly to changes in ocean temperatures (Favier et al., 2014; Joughin et al., 2014; Seroussi et al., 2014; Mengel and Levermann, 2014; Pollard et al., 2015; Fogwill et al., 2014); thus, it is critical to take variability into account for quantitative assessments.

The response of a real ice sheet to temperature increase is naturally much more complex than what can be described in a simple study such as the present paper. In a model study, Born and Nisancioglu (2012) observe mass loss acceleration of the northeastern GrIS as a response to warming. This part of the GrIS experiences comparatively little precipitation and thus increasing melt is not compensated for by increasing accumulation. However, the opposite has been shown to be the case for Antarctica. Frieler et al. (2015) show that increasing temperatures will increase Antarctic SMB on continental scales due to increasing precipitation. This is a case of accumulation-dominated mass balance where the curvature term in Eq. (6) has the opposite sign; thus, an underestimated temperature fluctuation would lead to an underestimation of the growth of the ice sheet.

When calculating the $\widetilde{f}$ 's in Eqs. (10) and (11) we assume a constant volume in the data from Robinson et al. (2012), but in reality the relative variations are as large as $9.5 \%$ when considering all the warming temperatures shown in Fig. 4 (Fig. S4). However, to draw the conclusion about the consequences of a $3{ }^{\circ} \mathrm{C}$ warming it is adequate to consider warmings less than $4^{\circ} \mathrm{C}$, and here the volume variation was less than $3 \%$ of the average (Fig. S5). Neglecting variations in volume does add uncertainty to our results, and it is not immediately clear to us how to quantify that uncertainty. Additionally, at time $t=200$ years where we extracted the SMB data from the simulations in Robinson et al. (2012), the ice sheet model simulations had not yet reached steady state; thus, expanding the analysis using a data set from ice sheet simulations in steady state would be desirable.

We have evaluated the consequences of the temperature fluctuation bias on long-term GrIS simulations and found that, if the full effects are taken into account with no further modifications, a significant effective temperature change would be required for an unbiased estimation of the equilibrium ice volume.

Code and data availability. The code is available online (Mikkelsen, 2018). Data used in this study were obtained from the authors of Robinson et al. (2012). 


\section{The Supplement related to this article is available online at https://doi.org/10.5194/tc-12-39-2018-supplement.}

Author contributions. TBM, AG and PD designed the study. TBM performed the data analysis. TBM, AG and PD wrote the article.

Competing interests. The authors declare that they have no conflict of interest.

Acknowledgements. We would like to thank Johannes Oerlemans for providing the original code for his model and Alexander Robinson for being very helpful in providing the data from their study. We are very grateful to Xavier Fettweis, Gerard Roe and an anonymous reviewer for valuable comments and suggestions that helped improve this paper. This work is part of the Dynamical Systems Interdisciplinary Network (DSIN) - Troels Bøgeholm Mikkelsen was financially supported by the Centre for Ice and Climate and the DSIN, both from the University of Copenhagen.

Edited by: Olivier Gagliardini

Reviewed by: Xavier Fettweis, Gerard Roe, and one anonymous referee

\section{References}

Abe-Ouchi, A., Saito, F., Kawamura, K., Raymo, M. E., Okuno, J., Takahashi, K., and Blatter, H.: Insolation-driven 100,000-year glacial cycles and hysteresis of ice-sheet volume, Nature, 500, 190-193, https://doi.org/10.1038/nature12374, 2013.

Abram, N. J., Mulvaney, R., Wolff, E. W., Triest, J., Kipfstuhl, S., Trusel, L. D., Vimeux, F., Fleet, L., and Arrowsmith, C.: Acceleration of snow melt in an Antarctic Peninsula ice core during the twentieth century, Nat. Geosci., 6, 404-411, https://doi.org/10.1038/NGEO1787, 2013.

Arnold, K. C. and MacKay, D. K.: Different methods of calculating mean daily temperatures, their effects on degree-day totals in the high Arctic and their significance to glaciology, Geogr. B., 123129, 1964

Barletta, V. R., Sørensen, L. S., and Forsberg, R.: Scatter of mass changes estimates at basin scale for Greenland and Antarctica, The Cryosphere, 7, 1411-1432, https://doi.org/10.5194/tc7-1411-2013, 2013.

Bindschadler, R. A., Nowicki, S., Abe-Ouchi, A., Aschwanden, A., Choi, H., Fastook, J., Granzow, G., Greve, R., Gutowski, G., Herzfeld, U., Jackson, C., Johnson, J., Khroulev, C., Levermann, A., Lipscomb, W. H., Martin, M. A., Morlighem, M., Parizek, B. R., Pollard, D., Price, S. F., Ren, D., Saito, F., Sato, T., Seddik, H., Seroussi, H., Takahashi, K., Walker, R., and Wang, W. L.: Ice-sheet model sensitivities to environmental forcing and their use in projecting future sea level (the SeaRISE project), J. Glaciol., 59, 195-224, https://doi.org/10.3189/2013JoG12J125, 2013.
Born, A. and Nisancioglu, K. H.: Melting of Northern Greenland during the last interglaciation, The Cryosphere, 6, 1239-1250, https://doi.org/10.5194/tc-6-1239-2012, 2012.

Box, G. E. P., Jenkins, G. M., and Reinsel, G. C.: Time Series Analysis - Forecasting and Control, John Wiley \& Sons, Inc., 4th edn., 2008.

Calov, R. and Greve, R.: A semi-analytical solution for the positive degree-day model with stochastic temperature variations, J. Glaciol., 51, 173-175, 2005.

Church, J., Clark, P., Cazenave, A., Gregory, J., Jevrejeva, S., Levermann, A., Merrifield, M., Milne, G., Nerem, R., Nunn, P., Payne, A., Pfeffer, W., Stammer, D., and Unnikrishnan, A.: Sea Level Change, book section 13, 1137-1216, Cambridge University Press, Cambridge, United Kingdom and New York, NY, USA, https://doi.org/10.1017/CBO9781107415324.026, www. climatechange2013.org, 2013.

Favier, L., Durand, G., Cornford, S. L., Gudmundsson, G. H., Gagliardini, O., Gillet-Chaulet, F., Zwinger, T., Payne, A. J., and Le Brocq, A. M.: Retreat of Pine Island Glacier controlled by marine ice-sheet instability, Nat. Clim. Change, 4, 117-121, https://doi.org/10.1038/nclimate2094, 2014.

Fettweis, X., Franco, B., Tedesco, M., van Angelen, J. H., Lenaerts, J. T. M., van den Broeke, M. R., and Gallée, H.: Estimating the Greenland ice sheet surface mass balance contribution to future sea level rise using the regional atmospheric climate model MAR, The Cryosphere, 7, 469-489, https://doi.org/10.5194/tc-7-469-2013, 2013.

Fogwill, C. J., Turney, C. S. M., Meissner, K. J., Golledge, N. R., Spence, P., Roberts, J. L., England, M. H., Jones, R. T., and Carter, L.: Testing the sensitivity of the East Antarctic Ice Sheet to Southern Ocean dynamics: past changes and future implications, J. Quaternary Sci., 29, 91-98, https://doi.org/10.1002/jqs.2683, 2014.

Frankignoul, C. and Hasselmann, K.: Stochastic climate models, Part II - Application to sea-surface temperature anomalies and thermocline variability, Tellus, 29, 289-305, https://doi.org/10.1111/j.2153-3490.1977.tb00740.x, 1977.

Frieler, K., Clark, P. U., He, F., Buizert, C., Reese, R., Ligtenberg, S. R. M., van den Broeke, M. R., Winkelmann, R., and Levermann, A.: Consistent evidence of increasing Antarctic accumulation with warming, Nat. Clim. Change, 5, 348-352, https://doi.org/10.1038/NCLIMATE2574, 2015.

Fyke, J. G., Miren, Vizcaíno, Lipscomb, W., and Price, S.: Future climate warming increases Greenland Ice Sheet surface mass balance variability, Geophys. Res. Lett., 41, 470-475, https://doi.org/10.1002/2013GL058172, 2014.

Golledge, N. R., Kowalewski, D. E., Naish, T. R., Levy, R. H., Fogwill, C. J., and Gasson, E. G. W.: The multi-millennial Antarctic commitment to future sea-level rise, Nature, 526, 421-425, https://doi.org/10.1038/nature15706, 2015.

Hasselmann, K.: Stochastic Climate Models - Part I. Theory, Tellus A, 28, 473-485, https://doi.org/10.3402/tellusa.v28i6.11316, 1976.

Hock, R.: Temperature index melt modelling in mountain areas, J. Hydrol., 282, 104-115, https://doi.org/10.1016/S00221694(03)00257-9, 2003.

Huybrechts, P., and de Wolde, J.: The dynamic response of the Greenland and Antarctic ice sheets to multiple-century climatic warming, J. Cli- 
mate, $\quad 12, \quad 2169-2188, \quad$ https://doi.org/10.1175/15200442(1999)012<2169:tdrotg>2.0.co;2, 1999.

IPCC: Summary for Policymakers, book section SPM, 1-30, Cambridge University Press, Cambridge, United Kingdom and New York, NY, USA, https://doi.org/10.1017/CBO9781107415324.004, www. climatechange2013.org, 2013.

Joughin, I., Smith, B. E., Shean, D. E., and Floricioiu, D.: Brief Communication: Further summer speedup of Jakobshavn Isbræ, The Cryosphere, 8, 209-214, https://doi.org/10.5194/tc-8-2092014, 2014.

Mengel, M. and Levermann, A.: Ice plug prevents irreversible discharge from East Antarctica, Nat. Clim. Change, 4, 451-455, https://doi.org/10.1038/nclimate2226, 2014.

Mikkelsen, T. B.: bogeholm/ice-sheets-fluctuating-temp: Influence of temperature fluctuations on equilibrium ice sheet volume, available at: https://doi.org/10.5281/zenodo.1134919, 2018.

Mudelsee, M.: Climate Time Series Analysis - Classical Statistical and Bootstrap Methods, Springer, https://doi.org/10.1007/97890-481-9482-7, 2010.

Muresan, I. S., Khan, S. A., Aschwanden, A., Khroulev, C., Van Dam, T., Bamber, J., van den Broeke, M. R., Wouters, B., Kuipers Munneke, P., and Kjær, K. H.: Modelled glacier dynamics over the last quarter of a century at Jakobshavn Isbræ, The Cryosphere, 10, 597-611, https://doi.org/10.5194/tc10-597-2016, 2016.

Nowicki, S. M. J., Payne, A., Larour, E., Seroussi, H., Goelzer, H., Lipscomb, W., Gregory, J., Abe-Ouchi, A., and Shepherd, A.: Ice Sheet Model Intercomparison Project (ISMIP6) contribution to CMIP6, Geosci. Model Dev., 9, 4521-4545, https://doi.org/10.5194/gmd-9-4521-2016, 2016.

Oerlemans, J.: A quasi-analytical ice-sheet model for climate studies, Nonlin. Processes Geophys., 10, 441-452, https://doi.org/10.5194/npg-10-441-2003, 2003.

Oerlemans, J.: Minimal Glacier Models, Igitur, Utrecht Publishing \& Archiving Services, Universiteitsbibliotheek Utrecht, second print in March 2011 (with some revisions) edn., 2008.

Pollard, D., DeConto, R. M., and Alley, R. B.: Potential Antarctic Ice Sheet retreat driven by hydrofracturing and ice cliff failure, Earth Planet. Sc. Lett., 412, 112-121, https://doi.org/10.1016/j.epsl.2014.12.035, 2015.

Reeh, N.: Parameterization of melt rate and surfaee temperature on the Greenland lce Sheet, Polarforschung, 5913, 113-128, 1991.

Ridley, J., Gregory, J. M., Huybrechts, P., and Lowe, J.: Thresholds for irreversible decline of the Greenland Ice Sheet, Clim. Dynam., 35, 1049-1057, https://doi.org/10.1007/s00382-009-0646$0,2010$.

Robinson, A., Calov, R., and Ganopolski, A.: Multistability and critical thresholds of the Greenland Ice Sheet, Nat. Clim. Change, 2, 429-432, https://doi.org/10.1038/nclimate1449, 2012.

Rodriguez, R. and Tuckwell, H. C.: Statistical properties of stochastic nonlinear dynamical models of single spiking neurons and neural networks, Phys. Rev. E, 54, 5585-5590, https://doi.org/10.1103/physreve.54.5585, 1996.

Roe, G. H. and Lindzen, R. S.: A one-dimensional model for the interaction between continental-scale ice sheets and atmospheric stationary waves, Clim. Dynam., 17, 479-487, https://doi.org/10.1007/s003820000123, 2001.
Roe, G. H. and O'Neal, M.: The response of glaciers to intrinsic climate variability: observations and models of late-Holocene variations in the Pacific Northwest, J. Glaciol., 55, 839-854, https://doi.org/10.3189/002214309790152438, 2009.

Seguinot, J.: Spatial and seasonal effects of temperature variability in a positive degree-day glacier surface mass-balance model, J. Glaciol., 59, 1202-1204, https://doi.org/10.3189/2013JoG13J081, 2013.

Seroussi, H., Morlighem, M., Rignot, E., Mouginot, J., Larour, E., Schodlok, M., and Khazendar, A.: Sensitivity of the dynamics of Pine Island Glacier, West Antarctica, to climate forcing for the next 50 years, The Cryosphere, 8, 1699-1710, https://doi.org/10.5194/tc-8-1699-2014, 2014.

Solgaard, A. M. and Langen, P. L.: Multistability of the Greenland Ice Sheet and the effects of an adaptive mass balance formulation, Clim. Dynam., 39, 1599-1612, https://doi.org/10.1007/s00382-012-1305-4, 2012.

Stocker, T., Qin, D., Plattner, G.-K., Alexander, L., Allen, S., Bindoff, N., Bréon, F.-M., Church, J., Cubasch, U., Emori, S., Forster, P., Friedlingstein, P., Gillett, N., Gregory, J., Hartmann, D., Jansen, E., Kirtman, B., Knutti, R., Krishna Kumar, K., Lemke, P., Marotzke, J., Masson-Delmotte, V., Meehl, G., Mokhov, I., Piao, S., Ramaswamy, V., Randall, D., Rhein, M., Rojas, M., Sabine, C., Shindell, D., Talley, L., Vaughan, D., and Xie, S.-P.: Technical Summary, book section TS, 33-115, Cambridge University Press, Cambridge, United Kingdom and New York, NY, USA, https://doi.org/10.1017/CBO9781107415324.005, www. climatechange2013.org, 2013.

van As, D., Bech Mikkelsen, A., Holtegaard Nielsen, M., Box, J. E., Claesson Liljedahl, L., Lindbäck, K., Pitcher, L., and Hasholt, B.: Hypsometric amplification and routing moderation of Greenland ice sheet meltwater release, The Cryosphere, 11, 1371-1386, https://doi.org/10.5194/tc-11-1371-2017, 2017.

van de Wal, R. S. W., and Oerlemans, J.: An energy balance model for the Greenland Ice Sheet, Global Planet. Change, 9, 115-131, https://doi.org/10.1016/0921-8181(94)90011-6, 1994.

von Storch, H. and Zwiers, F. W.: Statistical Analysis in Climate Research, Cambridge University Press, netlibrary edition edn., http: //www.leif.org/EOS/vonSt0521012309.pdf (last access: 1 April 2016), 2003.

Wake, L. and Marshall, S.: Assessment of current methods of positive degree-day calculation using in situ observations from glaciated regions, J. Glaciol., 61, 329-344, https://doi.org/10.3189/2015JoG14J116, 2015.

Weertman, J.: Stability of ice-age ice sheets, J. Geophys. Res., 66, 3783-3792, https://doi.org/10.1029/jz066i011p03783, 1961.

Weertman, J.: Rate of growth or shrinkage of nonequilibrium ice sheets, J. Glaciol., 5, 145-158, https://doi.org/10.1017/s0022143000028744, 1964.

Weertman, J.: Milankovitch solar radiation variations and ice age ice sheet sizes, Nature, 261, 17-20, https://doi.org/10.1038/261017a0, 1976. 